\title{
Genetic gain for yield in rice breeding and rice production in India to meet with the demand from increased human population
}

\author{
K. Muralidharan ${ }^{1, *}$, G. S. V. Prasad ${ }^{1}$, C. S. $\operatorname{Rao}^{1}$ and E. A. Siddiq ${ }^{2}$ \\ ${ }^{1}$ ICAR-Indian Institute of Rice Research, Rajendranagar, Hyderabad 500 030, India \\ ${ }^{2}$ Institute of Biotechnology, Professor Jayashankar Telangana State Agricultural University, Hyderabad 500 030, India
}

\begin{abstract}
Our objective was to estimate genetic gain for yields in genotypes tested in 11 rice ecosystems from 1995 to 2013 in India and compare the growth trend of human population and national rice grain production in 1974 to 2013. In each ecosystem, the check used remained the same over years but showed similar and significant increases along with top-3 genotypes and experimental mean grain yields derived from sets of genotypes that varied with the year. Therefore, when environmental effects were eliminated, there was no significant genetic gain in yield of genotypes. Annually human population grew linearly at $\mathbf{1 6 . 2 0 3}$ million persons and rice production at $\mathbf{1 . 9 4 3}$ million tonnes $(\mathrm{mt})$ during 1974-1994. This growth slowed during 19952013 in population by 16.131 million persons and in rice production by $1.2753 \mathrm{mt}$. Breeding for higher genetic yields should be restricted to the four mega environments which offer scope, and exploit the unfolding advancements in rice genomics. The national average yield of un-milled rice was $3.76 \mathrm{t} / \mathrm{ha}$. Evidence indicates that the potential yield in rice is $15-16 \mathrm{t} / \mathrm{ha}$ and yields of $10 \mathrm{t} / \mathrm{ha}$ is attainable in relatively riskfree irrigated $(\sim 20 \mathrm{~m}$ ha) and rainfed shallow lowland (11 m ha) ecosystems. Closing yield gap ( 6 t/ha) through corrective technological and policy interventions is urgently needed to ensure rice availability to match with the demands of growing population.
\end{abstract}

Keywords: Attainable yield, breeding, genetic gain, potential yield, mega environments, Oryza, population, production, rice.

IN the dynamic rice-breeding programme, genotypes with improvement in grain yields or in other traits of economic value compared to checks are identified through replicated multi-location trials across rice growing environments and released as varieties for commercial cultivation. Phenotypic performance of a plant is a function of both genetic and environmental factors and their interaction. The experimental mean grain yield derived from a cohort of genotypes tested across locations in an ecosystem denotes base yield of the breeding stock in that ecosystem.

\footnotetext{
*For correspondence. (e-mail: muralidharan_km@yahoo.com)
}

Universal environment is the potential of all possible environments in the target rice area for a projected variety. Therefore, each year, breeding lines are evaluated in nationally coordinated multi-environment tests (METs) by the All-India Coordinated Rice Improvement Project (AICRIP). During evaluation, yield, grain quality and resistance to biotic and abiotic stresses are ranked; breeding lines that show superiority compared to check cultivars ${ }^{1}$ are then selected. The mean grain yields of the top 3 genotypes, checks and breeding stock (experimental mean yields) can be considered to represent a hypothetical floating check of Jensen ${ }^{2}$ that adjusts to yield gains, if any, annually. Instead of considering the top-most entry alone, the mean performance of the top 3 ranking genotypes provides a better measure of changes if any, in the genetic potential of successively developed new breeding lines. Muralidharan et ll $^{3}$ analysed floating checks in the METs of AICRIP performed for the period 1974-1994. This study showed a negative trend in genotypes successively developed for rainfed upland ecosystem, indicating a significant $(P=0.05)$ decrease in rice yields of $1.3 \%$ or $41 \mathrm{~kg} / \mathrm{ha} /$ year. Further, they found a positive but nonsignificant trend in genotypes successively developed for rainfed shallow lowland, semideep water and deep water ecosystems; and a highly significant and positive increase in yields of $1.2 \%$ or $52 \mathrm{~kg} / \mathrm{ha} /$ year in genotypes bred for irrigated medium ecosystem. Such yield increase in genotypes tested in irrigated ecosystem was attributed to improved crop-husbandry skills and infrastructure development at test locations over the years ${ }^{3}$. Similar analyses were made on the grain yield performance of rice genotypes developed by breeders and tested worldwide from 1976 to 1997 in the International Rice Testing Programme (IRTP) or International Network for Genetic Evaluation of Rice (INGER) experiments by the International Rice Research Institute (IRRI) in different ecosystems ${ }^{4}$. The three floating checks in these international trials in rainfed upland and rainfed lowland ecosystems showed a negative trend, indicating a gradual decrease in grain yield by $2.4 \%$ or $72 \mathrm{~kg} / \mathrm{ha} /$ year; in irrigated ecosystem, the trend was positive, but non-significant. The ANOVA and regression with and without environmental effects ${ }^{5}$ by deducting check or experimental mean from 
the mean yield of top 3 genotypes were employed to estimate differences and gain in yield over time for the ecosystems and maturity groups. Muralidharan et $a l^{3}$ concluded that there was no evidence for either a genetic gain or loss in grain yields of genotypes developed for any of the ecosystems from 1974 to 1994. The lack of progress in yield over the years was more or less similar in the national (AICRIP) and international (IRRI) testing programmes $^{3,4}$. In 1995, few changes were effected in the constitution of AICRIP's tests with recognition of very early, early, mid-early, medium and late maturing genotypes suited to varied cropping systems and seasons in vogue in irrigated ecosystem. The change also included a separate trial for Basmati type genotypes in the irrigated ecosystem. The overall objective of the present study was to estimate genetic gains, if any, in the genotypes developed through intensive national breeding programme from 1995 to 2013 using the same methods employed in earlier studies ${ }^{3,4}$. Further, growth in national human population and national rice production between 1974 and 2013 were also estimated using annual grain production and population data of the Government of India ${ }^{6}$ to help plan and direct future rice research.

\section{Methods and material}

\section{Multi-environments tests in different ecosystems and data sets on grain yield}

During 1995-2013, as many as 9880 breeding lines were evaluated in AICIRPs tests. Nearly 7053 elite lines undervent at least three years of rigorous testing in multienvironmental tests (METs) ${ }^{7}$. AICRIP's experiments led to the identification and release of 573 varieties during 1995-2014 for commercial cultivation, either by the States or by the Centre. Data sets on grain yield assessment of breeding lines and checks in 2535 experiments executed between 1995 and 2013 were used for this study. The checks were both nationally released varieties (VC) and local checks (LC) that were commercial varieties grown widely at each test location. These experiments were performed at 117 locations in 26 states in India under direct seeded rainfed upland, rainfed shallow lowland, semideep water, deep water and irrigated ecosystems. Rainfed direct seeded upland experiments were made with two sets of genotypes, very early (up to $70 \mathrm{DF}$ (days to flowering)) and early (71-80 DF) genotypes and transplanted rainfed shallow lowland; semi-deep and deep water ecosystems were with medium (>110 DF) flowering genotypes. Experiments in irrigated ecosystems were made with five sets of very early (up to $80 \mathrm{DF}$ ), early (81-90 DF), mid-early (91-100 DF), medium (101$110 \mathrm{DF})$ and late $(>110 \mathrm{DF})$ flowering breeding lines. Further, a set of Basmati breeding lines with medium (>110 DF) flowering duration were also evaluated in exclusive experiments under irrigated ecosystem at 11 locations in the traditional Basmati growing states of Delhi, Haryana, Jammu and Kashmir, Punjab, Uttarakhand and Uttar Pradesh in India.

All AICRIP's experiments were conducted in randomized block designs with three replications. In rainfed upland experiments, seeds at the rate of $100 \mathrm{~kg} / \mathrm{ha}$ were sown directly in lines. Every test breeding stock was line sown in 10 rows, each of which was $5-10 \mathrm{~m}$ in length. A spacing of $15 \mathrm{~cm}$ between rows or lines was adopted in all these experiments. This direct seeding was also adopted at a spacing of $20 \mathrm{~cm}$ between rows and plants with the onset of monsoon rains in semi-deep water and deep water ecosystems. In rainfed shallow lowland and irrigated ecosystems, 30-day-old seedlings were transplanted in experimental plots, at a spacing of $20 \mathrm{~cm}$ between rows and $15 \mathrm{~cm}$ between plants. The experimental plot size varied with locations; but in most cases the minimum sub-plot size was $10 \mathrm{~m}^{2}$. Efforts were made at all locations to ensure crop growth of test breeding stock by adjusting the time of direct seeding or planting, and fertilizer application to suit maturity period or ecosystem where a particular experiment was conducted. Fertilizer rates and insecticide applications were usually decided by the co-operator. In all treatment plots, one border row on each side was excluded and grain from the remaining plants were harvested and expressed as $\mathrm{t} / \mathrm{ha}$ at $14 \%$ moisture $^{3,4}$.

\section{Assessment of genetic gain}

The methodologies employed for the yield assessment to match with rice cropping season and crop management were approximately uniform. Individual trial data were scrutinized and analysed by AICRIP at the end of each year. Data from experiments registering $>20 \%$ coefficient of variation $(\mathrm{CV})$ were rejected. From the results presented by AICRIP for each trial, and for each test year in different ecosystems during 1995-2013 (ref. 7), the mean yields of top 3 genotypes were derived across all test sites. Similarly, check mean yield and experimental mean yield estimated year-wise were also derived and saved for later analysis. Occasionally, when a standard designated check was not used in a trial, the local check mean was considered. Details on the number of genotypes, location and experiments involved in this study are summarized in Table 1. Analysis of variance was computed for each trial duration-wise under different ecosystems $^{8,9}$. Initially, the variances of mean grain yields in the top 3 genotypes, checks and experimental means were analysed using $F$-test. Wherever variance was homogenous, the data sets were pooled trial-wise. Mean comparisons were made for equality by $t$-test on the basis of analysis of variance. If variance was not homogenous, weighted means were derived. Ecosystem-wise, Bartlett's 
test of homogeneity of variances of mean grain yields in check varieties was applied. For each test year in different ecosystems, the three floating checks namely, top 3 genotypes mean grain yield, checks mean grain yield (both national and local), and experimental mean grain yield of test genotypes evaluated were calculated across locations. The linear regressions were performed with mean grain yields recorded by the three floating checks over years, to estimate the change in yields due to genetic and environmental causes. In whichever ecosystem the mean grain yields showed a statistically significant increase or decrease, genetic gain or loss was tested. For this in each test year under different ecosystems, the check mean or experimental mean yield was deducted from the top 3 genotypes mean grain yield to eliminate the environmental effect, and regression analyses were repeated to find genetic gain or loss, if any, for grain yield. The criteria used to identify the best-fit models were significance of model parameters (Student's $t$-test), coefficients of determination $\left(R^{2}\right.$ and $R_{\mathrm{a}}^{2}$ that adjusts for the number of explanatory terms in the model relative to the number of data points), and the lowest root means square of standard error (RMSE) while meeting the assumptions of normality, independence and homogenous variance in regression analysis.

\section{Assessment of national production gain}

Previously published data from 1974 to 2013 were retrieved for both annual all-India human population levels and all-India rice grain production ${ }^{6}$. The trend in population and rice grain production was analysed by considering two time frames, for 1974-1994, to compare with published estimates on progress in rice breeding ${ }^{3}$ and for 1995-2013, to assess progress made later. Global rates of yield increase in grain production have been decidedly linear for most crop species, especially for rice ${ }^{10,11}$. Therefore, linear regressions were performed with these data sets on rice grain production and population in India.

\section{Results}

\section{Comparison of mean grain yields}

During 1995-2013, 9880 breeding lines including checks, both nationally released varieties (VC) and local checks (LC) that were commercial varieties grown widely at each test location, were evaluated in AICIRPs tests under different ecosystems (Table 1). The mean grain yields recorded in rainfed upland ecosystem by very early and early flowering check varieties evaluated in experiments were compared (Table 2). In general, there was no significant difference between the varieties used as checks in rainfed upland ecosystem. The only exception was in the very early group where the LC exhibited significant dif- ferences in the mean grain yields compared to Heera (VC). The highest yield recorded was $2.07 \mathrm{t} / \mathrm{ha}$ by LC in very early group and $2.9 \mathrm{t} / \mathrm{ha}$ by Tulasi (VC) in early group. In rainfed lowland ecosystem, highly significant differences were observed in the mean grain yields of Salivahana (VC) only compared to LC. The highest yield recorded was $4.6 \mathrm{t} / \mathrm{ha}$ in LC. In semi-deep water ecosystem, significant differences were observed only in the mean grain yields of Utkalprabha (VC) compared to Purnendu (VC) or other LC. Again, the highest mean grain yield recorded was $3.0 \mathrm{t} / \mathrm{ha}$ in LC. In deep water ecosystem, none showed any significant difference in the mean grain yields. The LC recorded the highest yield of $2.4 \mathrm{t} / \mathrm{ha}$. In irrigated ecosystem, highly significant differences were observed in a few comparisons of the mean grain yields, Anjali or Vandana with Aditya (very early VC); Annada, Govind or Narendra97 (VC) with LC (early); Vikas with Sasyasree and IR64 (VC) or LC (midearly); Jaya or Suraksha (VC) with LC (medium); Savitri (VC) with LC (late) and Tarori Basmati with Pusa Basmati 1 (VC) or LC (in Basmati group). The highest mean grain yields recorded were $3.9 \mathrm{t} / \mathrm{ha}$ in Anjali (very early VC); $4.6 \mathrm{t} /$ ha in LC (early and mid-early), $4.9 \mathrm{t} / \mathrm{ha}$ in LC (medium and late flowering), and $3.7 \mathrm{t} / \mathrm{ha}$ in Tarori Basmati (VC in Basmati group) genotypes. Variances depended on the number of tests or the number of test entries in an experiment. The Bartlett's test showed that variances of the grain yields in the check varieties were homogenous in all ecosystems.

\section{Performance of genotypes in rainfed upland ecosystem}

During 1995-2013, elite breeding lines in very early (441) and early flowering groups (855) were tested in 440 experiments in rainfed upland (direct seeded) ecosystem (Table 1) and the best fit linear regression models were developed using data from these experiments (Figure 1). The mean grain yields of top 3 genotypes were higher than checks and experimental mean grain yields in very early and early groups. However, the experimental mean grain yields were higher than check mean grain yields in the very early group but were lower in the early group of genotypes. The linear regression models on the top 3 genotypes and check mean grain yields showed a positive but non-significant increase in the very early group, and a negative non-significant decrease in the early group. The yields of genotypes tested in rainfed upland ecosystem over years had produced similar grain yields indicating neither any genetic gain nor a loss.

\section{Performance of genotypes in rainfed shallow lowlands, semi-deep water and deep water ecosystems}

During 1995-2013, elite breeding lines in rainfed shallow lowlands (469), semi-deep water (436) and deep water 
Table 1. Particulars of trials in different rice ecosystems in the all-India co-ordinated rice improvement experiments performed between 1995 and 2013

\begin{tabular}{|c|c|c|c|c|c|c|c|}
\hline \multirow[b]{2}{*}{ Check varieties } & \multirow[b]{2}{*}{$\begin{array}{c}\text { Cross/ } \\
\text { selection }\end{array}$} & \multirow[b]{2}{*}{$\begin{array}{l}\text { Year released } \\
\text { as variety }\end{array}$} & \multirow[b]{2}{*}{$\begin{array}{l}\text { Years tested } \\
\text { no. (period) }\end{array}$} & \multicolumn{2}{|c|}{$\begin{array}{c}\text { Entries } \\
\text { tested (no.) }\end{array}$} & \multicolumn{2}{|c|}{$\begin{array}{c}\text { Experiments } \\
\text { performed (no.) }\end{array}$} \\
\hline & & & & Range & Total & Range & Total \\
\hline \multicolumn{8}{|c|}{ Rainfed upland (direct-seeded) ecosystem - very early (up to $70 \mathrm{DF}$ ) } \\
\hline Heera & CR 404-48/CR 289-1208 & 1989 & 19 & $9-46$ & 441 & $6-22$ & 207 \\
\hline Vandana & C 22/Kalakeri & 2002 & $(1995-2013)$ & & & & \\
\hline \multicolumn{8}{|c|}{ Rainfed upland (direct-seeded) ecosystem - early (71-80 DF) } \\
\hline Annada & MTU 15/Waikoku & 1987 & 19 & $20-64$ & 855 & $5-26$ & 233 \\
\hline Tulasi & Rasi/Fine Gora & 1988 & $(1995-2013)$ & & & & \\
\hline Narendra 97 & N 22/Ratna & 1992 & & & & & \\
\hline \multicolumn{8}{|c|}{ Rainfed shallow lowland ecosystem (>110 DF) } \\
\hline Dhanrasi & B 32 Sel. 4/O. rufipogon C4//B127 & 2002 & 9 & $33-67$ & 469 & $8-25$ & 132 \\
\hline Swarna & Vasistha/Mahsuri & 1979 & (1995-1999 and & & & & \\
\hline Sabita & Pureline sel. from Boyan & 1986 & 19 & $9-52$ & 436 & $5-13$ & 156 \\
\hline Purnendu & Patnai 23/Jaladhi 2 & 1994 & $(1995-2013)$ & & & & \\
\hline UtkalPrabha & Waikoku/CR 1014 & 1983 & & & & & \\
\hline \multicolumn{8}{|c|}{ Deep water ecosystem (>110 DF) } \\
\hline Jalmagna & Sel. from Badhon & 1969 & 11 & $12-34$ & 237 & $2-7$ & 42 \\
\hline Dinesh & Jaladhi 2/Pankaj & 1988 & $(2003-2013)$ & & & & \\
\hline \multicolumn{8}{|c|}{ Irrigated (very early) ecosystem (up to $80 \mathrm{DF}$ ) } \\
\hline Heera & CR 404-48/CR 289-1208 & 1989 & 14 & $11-30$ & 245 & $1-12$ & 71 \\
\hline Anjali & RR 19-2/RR 149-1129 & 2001 & $(1999-2012)$ & & & & \\
\hline Vandana & C 22/Kalakeri & 2002 & & & & & \\
\hline \multicolumn{8}{|c|}{ Irrigated (early) ecosystem (81-90 DF) } \\
\hline Annada & MTU 15/Waikoku & 1987 & 15 & $30-64$ & 725 & $8-26$ & 247 \\
\hline Govind & IR 20/IR 24 & 1982 & $(1999-2013)$ & & & & \\
\hline Narendra 97 & N 22/Ratna & 1992 & & & & & \\
\hline \multicolumn{8}{|c|}{ Irrigated (mid-early) ecosystem (91-100 DF) } \\
\hline IR 64 & IR 5657-33-2-1/IR 2061-465-1-5-5 & 1991 & & & & & \\
\hline \multicolumn{8}{|c|}{ Irrigated (medium) ecosystem (101-110 DF) } \\
\hline Jaya & TN1/T141 & 1968 & 19 & $44-64$ & 1126 & $14-38$ & 482 \\
\hline Suraksha & Sasyasree/MR 1523 & 1979 & $(1995-2013)$ & & & & \\
\hline \multicolumn{8}{|c|}{ Rainfed (late) ecosystem (>110 DF) } \\
\hline Savithri & Pankaj/Jagannath & 1983 & 14 & $49-64$ & 785 & $4-22$ & 231 \\
\hline Swarna & Vasistha/Mahsuri & 1979 & $(2000-2013)$ & & & & \\
\hline \multicolumn{8}{|c|}{ Irrigated (Basmati) ecosystem (up to $110 \mathrm{DF}$ ) } \\
\hline Pusa Basmati 1 & Pusa $167 /$ Karnal local & 1989 & 19 & $20-40$ & 540 & $4-21$ & 203 \\
\hline Taroari Basmati & Pure line sel. from HBC 19 & 1996 & $(1995-2013)$ & & & & \\
\hline
\end{tabular}

DF, Days to flowering.

(237) ecosystems were tested in 330 experiments (Table 1). The experimental mean yields were lower than check mean grain yields of all genotypes tested in rainfed shallow lowland, semi-deep water and deep water ecosystems. The mean grain yields of the top 3 genotypes were relatively higher than both check and experimental mean grain yields in all these rainfed ecosystems. The yield of the three floating checks showed non-significant differences in yields of genotypes in both rainfed shallow and deep water ecosystems (Figures 1 and 2). Only in semideep water ecosystem, the linear regression models on the top 3 genotypes, check and experimental mean yields over years showed highly significant and positive increases (66 to $91 \mathrm{~kg} / \mathrm{ha} /$ year). Yet, the genetic gain derived by subtracting check or experimental mean grain yields from top 3 genotype mean grain yields showed non-significant increase or nearly static rice yields in genotypes bred for semi-deep water ecosystem. The analysis showed a lack of any genetic gain in the genotypes developed during 1995-2013 for rainfed shallow lowland (Figure 1), semi-deep water and deep water ecosystems (Figure 2).

\section{Performance of genotypes in irrigated ecosystems}

During 1995-2013, elite breeding lines in irrigated very early (245), early (725), mid-early (1194), medium (1126), late (785) and Basmati (540) ecosystems were 
Table 2. Comparison of mean grain yields $(\mathrm{t} / \mathrm{ha})$ and variance of mean grain yields among the check varieties in the all-India co-ordinated rice improvement experiments performed between 1995 and 2013



*DF, Days to flowering; Variances of mean grain yields in checks (upper diagonal values represent $F$-values); Mean grain yields (t/ha) in checks (lower diagonal values represent $t$-values) (ns, Non-significant; $* P=0.05 ; * * P=0.01$ ). 

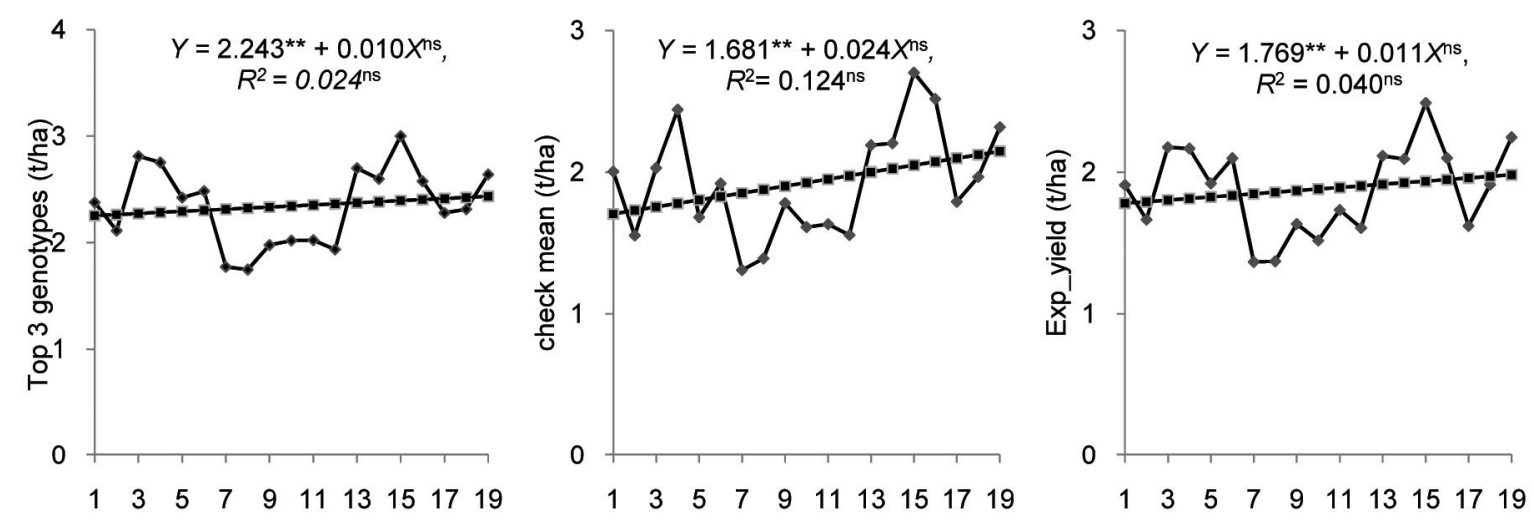

Rainfed upland very early ecosystem (19 years from 1995 to 2013)
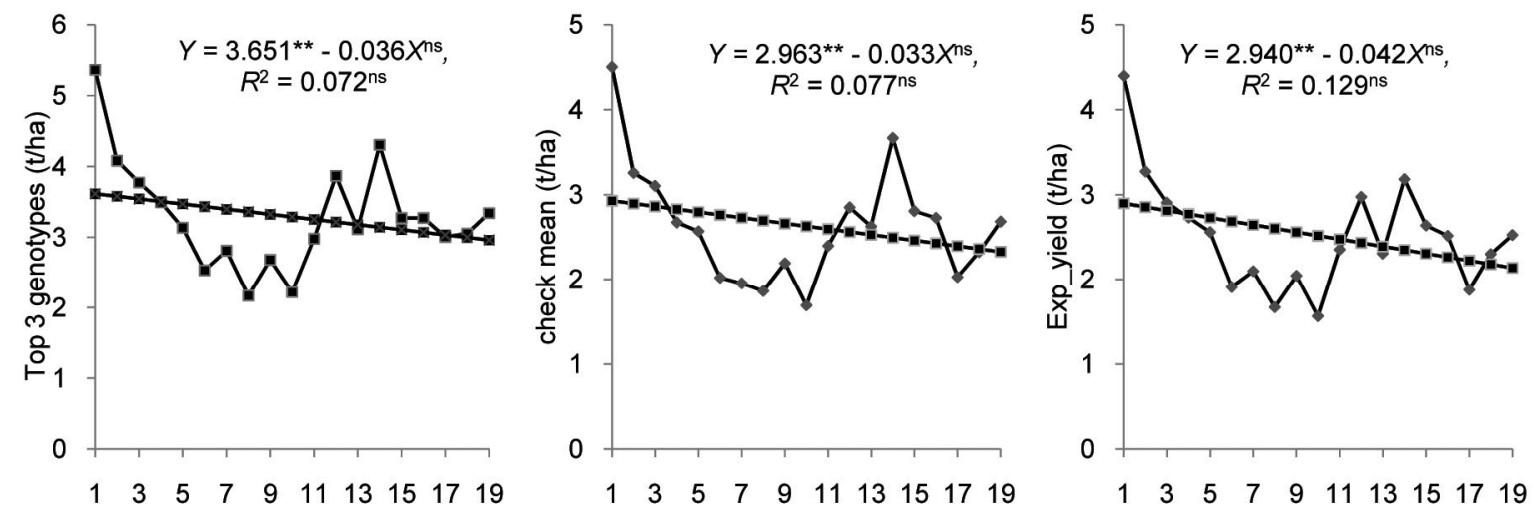

Rainfed upland early ecosystem (19 years from 1995 to 2013)


Rainfed shallow lowland ecosystem (9 years from 1995 to 1999 and 2010 to 2013)

Figure 1. Performance of the three floating checks - top 3 genotypes, check and experimental mean grain yields across locations over years in rainfed ecosystems. Line fit represents the predicted mean grain yields $(\mathrm{ns}=$ non-significant; $* P=0.05 ; * * P=0.01)$.

tested in 1765 experiments (Table 1). The mean grain yields of the top 3 genotypes were higher than both check and experimental mean grain yields in all these irrigated ecosystems. The experimental mean yields were lower than the check mean grain yields in early, mid-early, medium, and late flowering genotypes; it was higher only in the very early group (Figures 3 and 4). In Basmati group, the top 3 genotypes mean grain yields were higher than both check and experimental mean grain yields (Figure
5). The experimental mean yields were also higher than the check mean grain yields. The linear regression models on the top 3 genotypes, check and experimental mean yields over time showed significant and positive increases in irrigated very early (106-132 kg/ha/year), irrigated early $(61-81 \mathrm{~kg} / \mathrm{ha} /$ year) and irrigated medium (30$35 \mathrm{~kg} / \mathrm{ha} /$ year) ecosystems. Similarly, significant and positive increases were found in the yields of the three floating checks in Basmati group of genotypes 



Semideep water ecosystem (17 years from 1995 to 2007 and 2010 to 2013)
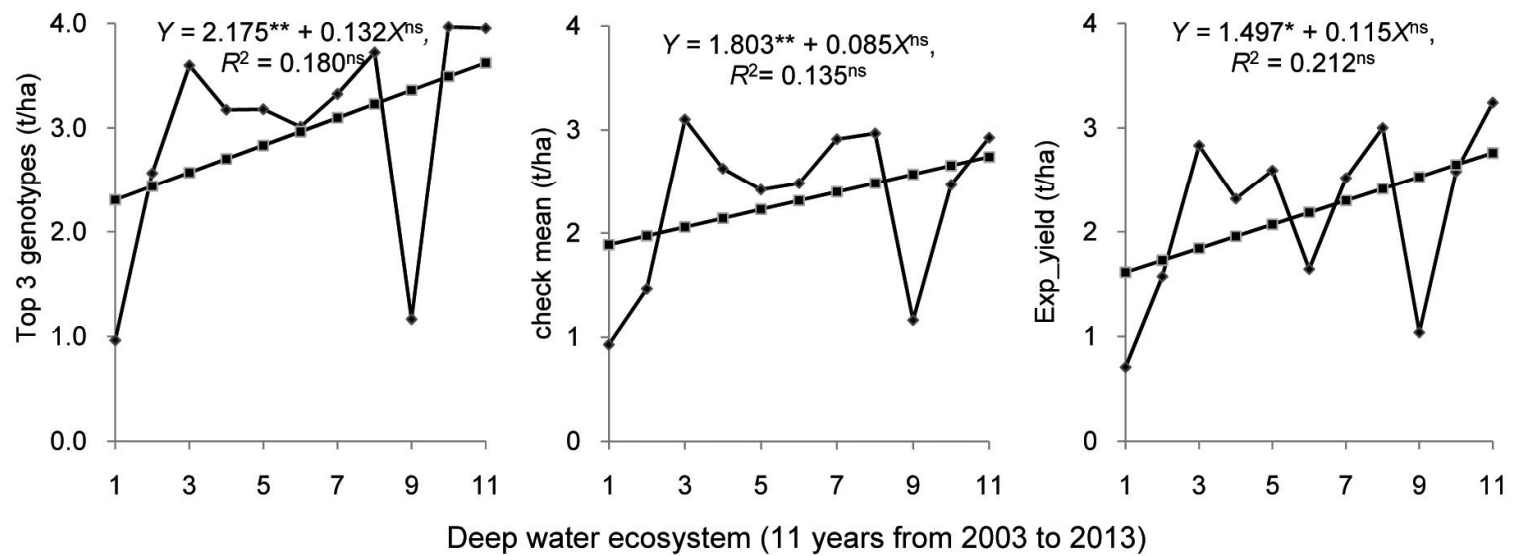

Figure 2. Performance of the three floating checks - top 3 genotypes, check and experimental mean grain yields across locations over years and genetic gain or loss in yield in semi-deep water and deep water ecosystems. Line fit represents the predicted mean grain yields (ns $=$ non-significant; $* P=0.05 ; * * P=0.01$ ). $\mathrm{G}$, In each test year, check or experimental mean yield was deducted from the top 3 genotypes mean grain yield to eliminate the environmental effect, and regression analyses were repeated to find genetic gain or loss in yield.

(47-59 kg/ha/year). However, the genetic gain derived by subtracting check mean or experimental grain yields from the top 3 genotypes mean grain yields showed nonsignificant increase and nearly static yields in the genotypes (including Basmati genotypes) bred for these irrigated ecosystems.

\section{Performance of national rice grain production in farms}

The national rice grain production in India is estimated as milled rice that is directly consumed by humans. Comparisons were made on the growth in human population and rice production during two successive periods. Linear regression modelling, using published data on both human population and rice production progress in the first phase of 21 years from 1974 to 1994 coinciding with an earlier study period on genetic gain through rice breeding by Muralidharan et al. ${ }^{3}$, clearly indicated highly significant linear relationships (Figure 6). Annually the population grew at 16.203 million persons while rice grain production increased by 1.943 million tonnes. Further, the value of coefficient of determination $\left(R^{2}\right)$ explained $99.7 \%$ variation in population growth and $87.5 \%$ variation in rice grain production increase. Similar highly significant linear relationships were detected in the growth of human population and national rice grain production during the 


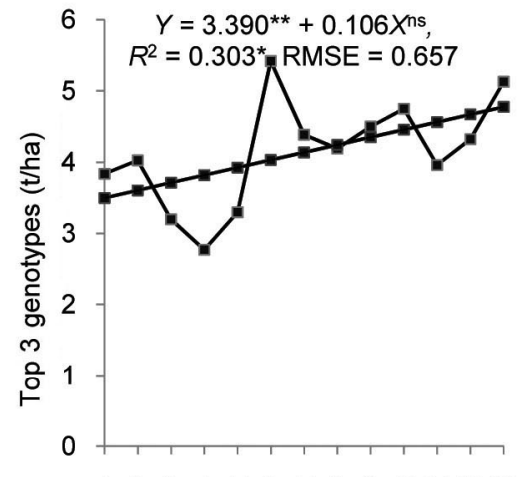

$\begin{array}{lllllllllll}1 & 2 & 3 & 4 & 5 & 6 & 7 & 8 & 9 & 10111213\end{array}$

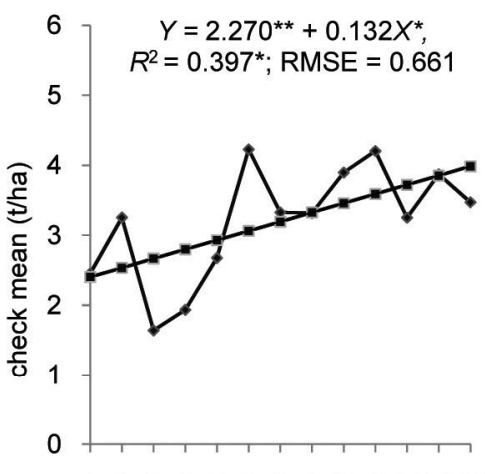

12234556788910111213

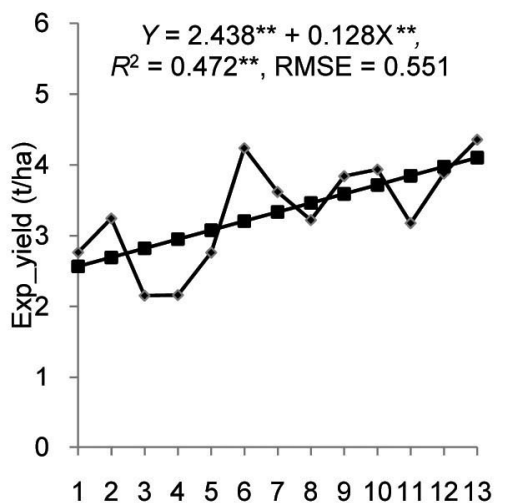

1.5 Top 3 genotype means - Exp_mean yield (t/ha)



Irrigated very early ecosystem (13 years from 1999 to 2009 and 2011-2012)
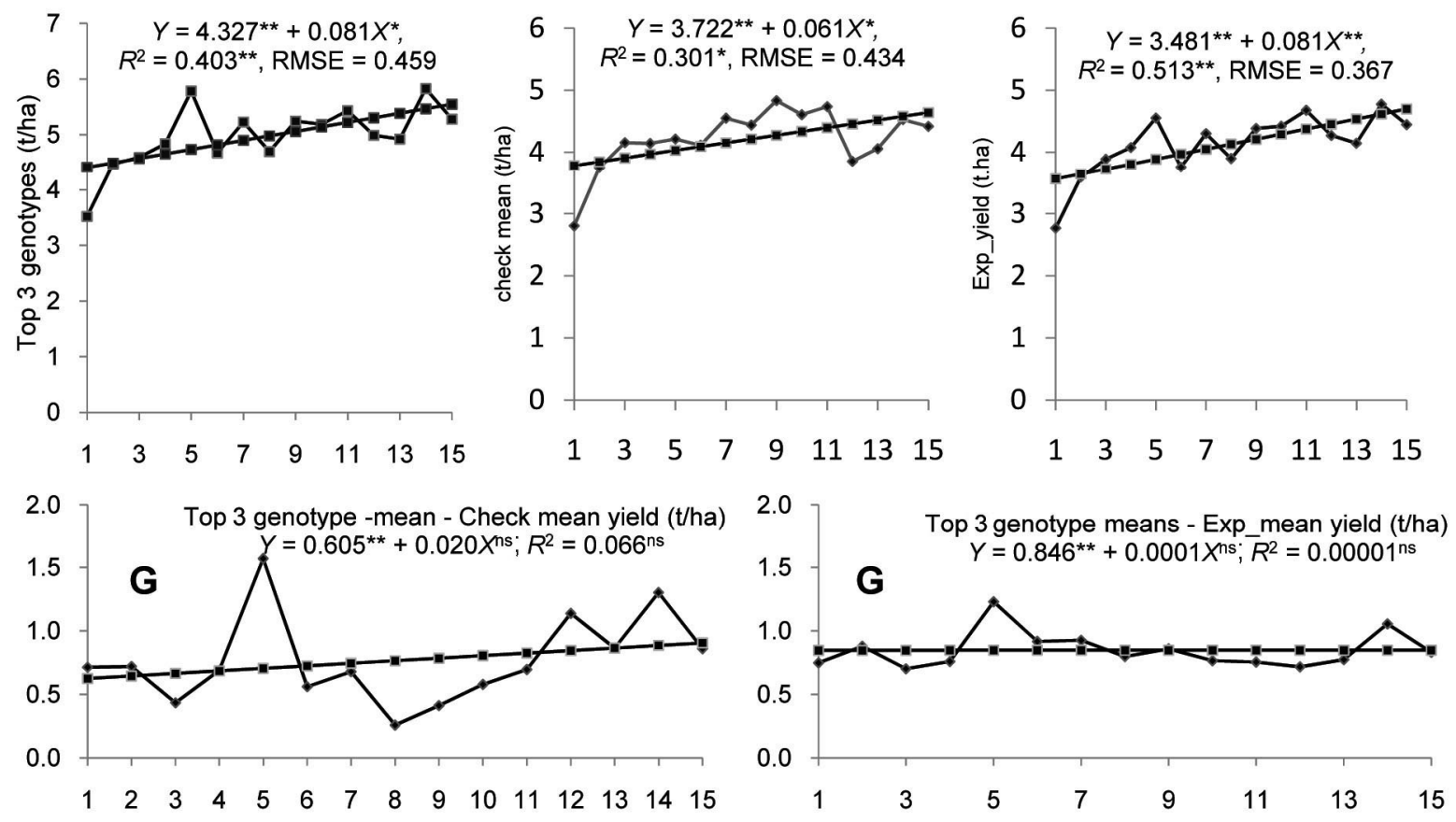

Irrigated early ecosystem (15 years from 1999 to 2013)

Figure 3. Performance of the three floating checks - top 3 genotypes, check and experimental mean grain yields across locations over years and genetic gain or loss in yield in irrigated very early and irrigated early ecosystems. Line fit represents the predicted mean grain yields (ns $=$ non-significant; $* P=0.05 ; * * P=0.01$ ). $\mathrm{G}$, In each test year, check or experimental mean yield was deducted from the top 3 genotypes mean grain yield to eliminate the environmental effect, and regression analyses were repeated to find genetic gain or loss in yield.

second phase of 19 years from 1995 to 2013. Annually the population grew at 16.131 million persons while rice grain production increased by 1.2753 million tonnes. Further, the value for coefficient of determination $\left(R^{2}\right)$ ex- plained $99.3 \%$ variation in population growth and $63.9 \%$ variation in rice grain production increase. In the linear models developed on the growth of human population and rice grain production, the $R_{\mathrm{a}}^{2}$ value also remained 

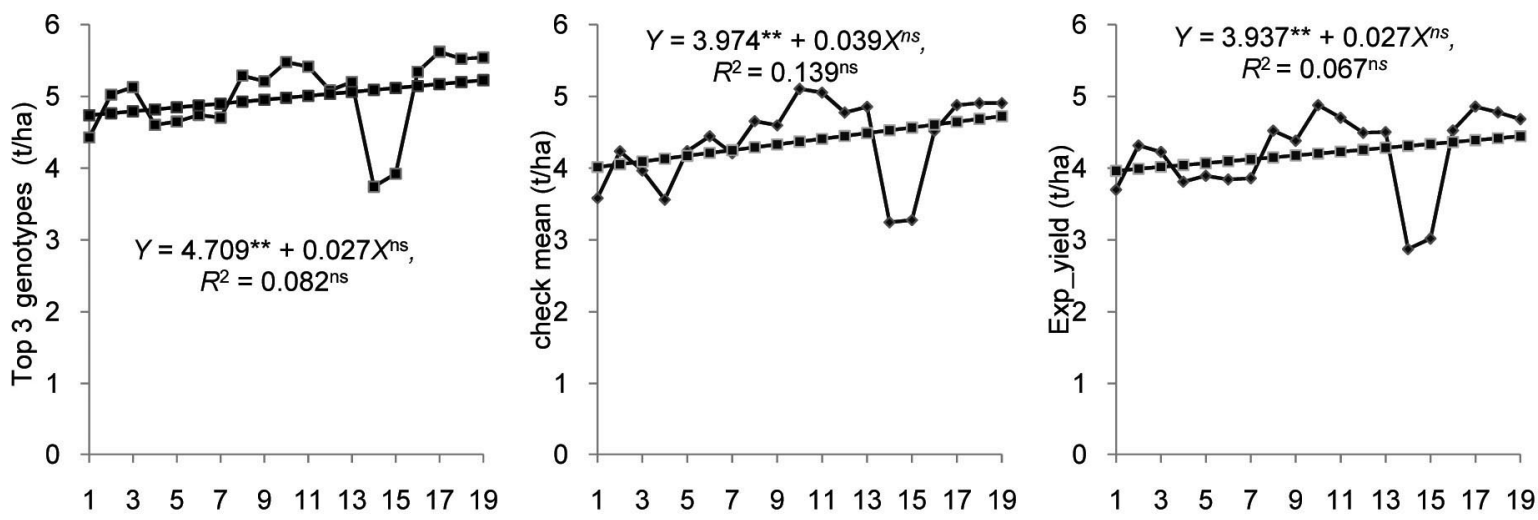

Irrigated ecosystem mid-early ecosystem (19 years from 1995 to 2013)
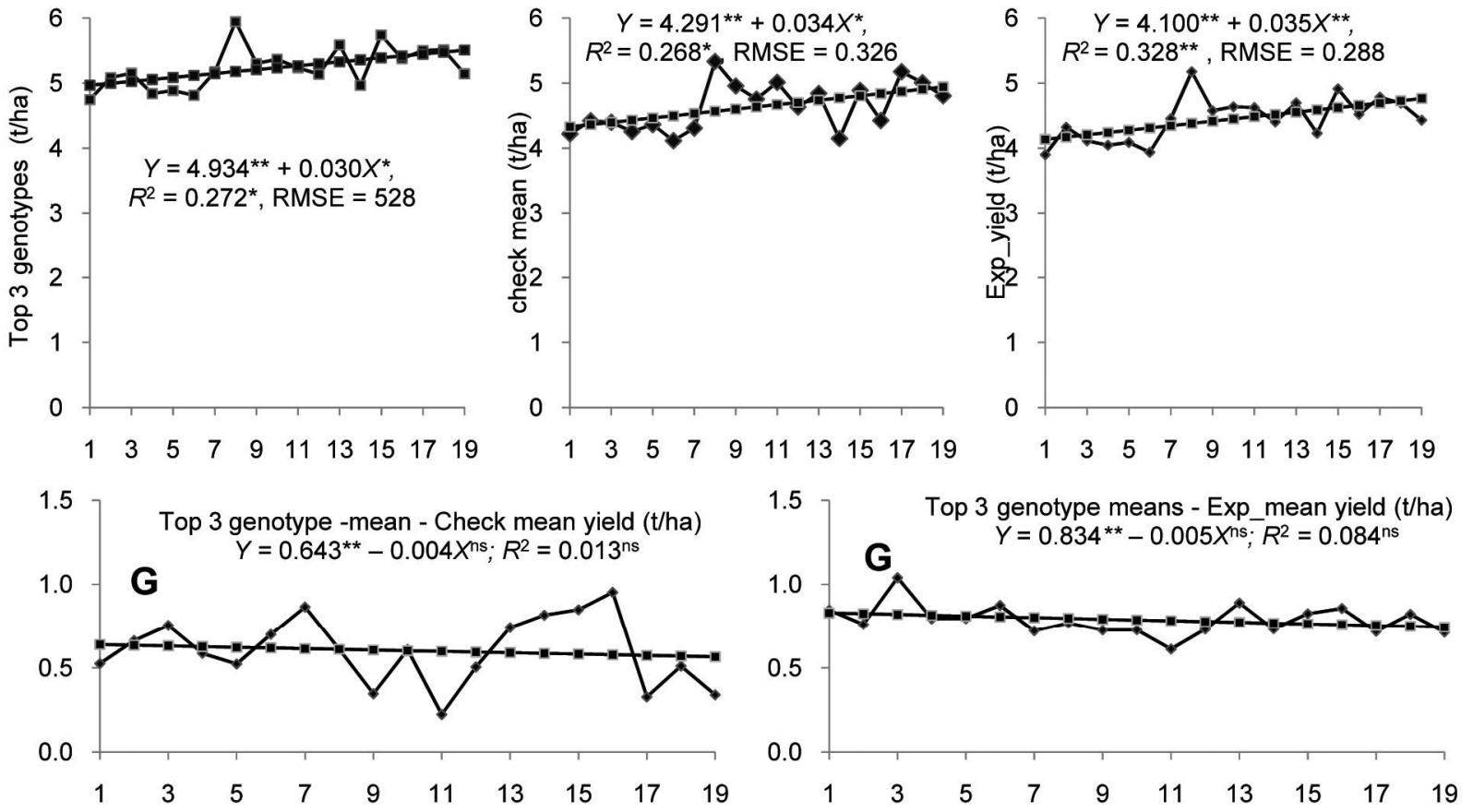

Irrigated medium ecosystem (19 years from 1995 to 2013)


Irrigated late ecosystem (14 years from 2000 to 2013 )

Figure 4. Performance of the three floating checks - top 3 genotypes, check and experimental mean grain yields across locations over years and genetic gain or loss in yield in irrigated mid-early, medium and late ecosystems. Line fit represents the predicted mean grain yields (ns = nonsignificant; $* P=0.05 ; * * P=0.01)$. G, In each test year, check or experimental mean yield was deducted from the top 3 genotypes mean grain yield to eliminate the environmental effect, and regression analyses were repeated to find genetic gain or loss in yield. 

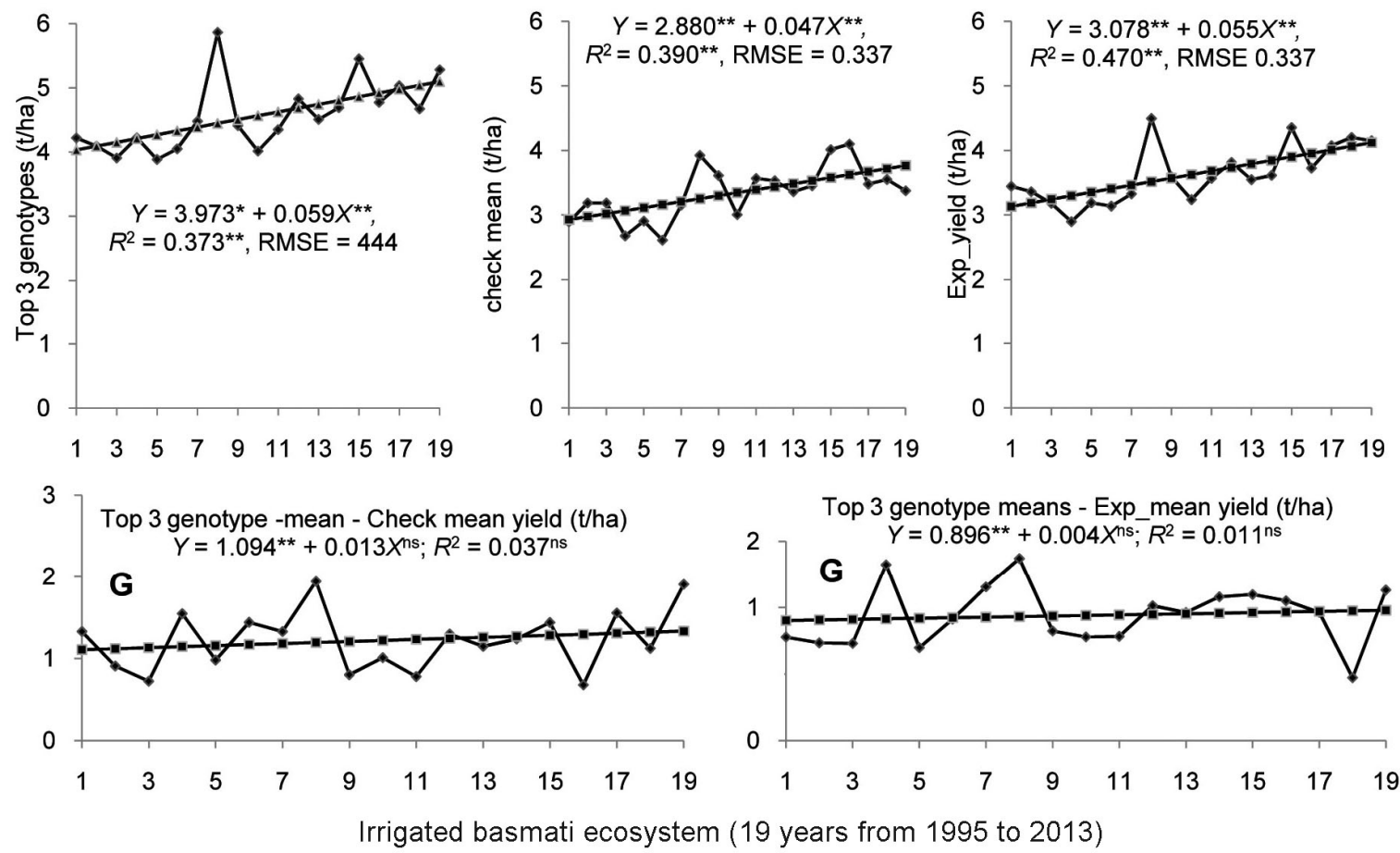

Figure 5. Performance of the three floating checks - top 3 genotypes, check and experimental mean grain yields across locations over 19 years from 1995 to 2013 and genetic gain or loss in yield in irrigated Basmati ecosystem. Line fit represents the predicted mean grain yields ( $\mathrm{ns}=$ non-significant; $* P=0.05 ; * * P=0.01)$. G, In each test year, check or experimental mean yield was deducted from the top 3 genotypes mean grain yield to eliminate the environmental effect, and regression analyses were repeated to find genetic gain or loss in yield.

close to $R^{2}$ value indicating that all parameters in the model were significant. A comparison of the two periods brought forth the decreasing trends in both annual population growth (by 72,000 persons) and rice grain production growth (by 667,700 tonnes) between 1995 and 2013.

\section{Discussion}

\section{Estimating gains in cereal crop yields}

Three different methods were used to find yield increases in cereal crops. The first one is based on the use of historical data on annual production at the level of country, state or region ${ }^{12}$; it provides a measure of production increase but does not indicate proportion attributable to genetic gain, as the farm yield is influenced by several non-genetic factors like fertilizer, irrigation, protection against stresses and the intensity of other crop management practices adopted ${ }^{10}$. The second method is to use the historical set of data on performance of genotypes in national or international trials to derive the genetic gain achieved in yield ${ }^{3,4,13}$. The third method to estimate genetic yield gain is to conduct yield trials with an array of generated breeding lines and cultivars, checks or standards using a set of agronomical practices ${ }^{14-16}$. These trials are often restricted to experiments for a few seasons and years, and ignore the effects of a wide range of envi- ronmental conditions and ever-changing crop production practices used in testing older genotypes. Retrospective physiology on genetic progress in tropical rice is also hampered by concerns over the validity of side-by-side comparisons of historic sets of cultivars ${ }^{17}$. Our analysis is limited to genetic yield gain in rice breeding, and to gains in rice grain production and population growth in India using historical data.

\section{Genetic yield gain in cereal crop genotypes through plant breeding}

Historical series of genotypes have been used in several countries to assess the genetic gains in cereal crops achieved during a period of time through plant breeding $^{3,4,13,18-21}$. Extensive reviews reveal that the estimated genetic gain varies with crop, country and period; the trend of genetic gain is extremely low since the introduction of improved varieties during the early period. Gain for yield in wheat varied with country and period of breeding duration. It was computed at $0.51 \%$ per year in the UK from 1900 to 1985 (ref. 18), $0.66 \%$ per year in France from 1962 to 1988 (ref. 22), 0.68\% per year in USA from 1919 to 1987 (ref. 23), and $0.70 \%$ per year in Siberia from 1900 to 2008 (ref. 21). The improvements of yield potential in Brazilian wheat cultivars through breeding and crop management practices enabled a growth of 



Figure 6. Trend in progress of population (million) and milled rice grain production (million tonne) in India (40 years from 1974 to 2013). Line fit represents the predicted mean grain yields $(* * P=0.01)$.

$44.9 \mathrm{~kg} / \mathrm{ha} /$ year between 1940 and 1992 (ref. 24). The genetic yield gains in wheat in Chile for the period 1968 1993 were 18 and $24 \mathrm{~kg} / \mathrm{ha} /$ year for spring and winter cultivars respectively ${ }^{25}$. However, other studies of spring wheat have shown that the genetic gain over a longer period of time (1920-2005) had two phases, one before 1960, with almost no gain, and a second after 1960, during which the genetic gain averaged $61 \mathrm{~kg} / \mathrm{ha} / \mathrm{year}^{26}$. In the UK, the genetic gain has also been $61 \mathrm{~kg} / \mathrm{ha} /$ year over the last 20 years during 1988-2007 (ref. 17). However, a lower genetic gain $(23 \mathrm{~kg} / \mathrm{ha} /$ year $)$ has been reported for spring wheat in Mexico under irrigated conditions over the last 30 years $^{17}$. The genetic gain for wheat was reported to range between 32 and $72 \mathrm{~kg} / \mathrm{ha} /$ year in three provinces in China for cultivars released between 1960 and 1990 (ref. 27). The evidence of a non-significant increase during 1970-2000 suggests that a plateau was reached for wheat yield gains in Spain ${ }^{15}$, very similar to reports from other countries ${ }^{17}$. The genetic gain was $39 \mathrm{~kg} / \mathrm{ha} /$ year for two-row barley in Germany for the period 1968-2003 (ref. 28), and was $36 \mathrm{~kg} / \mathrm{ha} /$ year for oat in Italy for the period 1969-2004 (ref. 29). The genetic gain of wheat and barley after the 1960s is mainly attributed to modifications of plant habit, especially reduction in plant height and hence non-lodging at high levels of nutrient applications and increased harvest index and grains per unit area ${ }^{30}$.
Globally the genetic gain of $0.88 \%$ per year in maize was reported for the period 1962-1988 (ref. 31). But, when genetic gain for yield in maize was computed for each environment in which field experiments were conducted, the range of variation was greater than $400 \%$ indicating a very high dependence of estimated genetic gains on environmental conditions ${ }^{15}$. This suggests that only improvement of plant type in the crop contributed to the progress in genetic yield and other non-genetic factors, such as appropriate agricultural public policies including economic incentives had facilitated adoption of recommended management practices. Previous studies also attributed such dissimilarities in yields in experiments to the different yield potential of environments ${ }^{22}$. It is not easy to assess the genetic gain, especially when environmental variations are large that cause proportionately large yield fluctuations between years. The bias created by the assessment of yield gains in only one environment was overcome in AICRIP tests by conducting experiments under a wide range of environmental conditions representing the many growing conditions encountered in 43 million ha of rice cultivation ${ }^{7}$.

Five decades of intensive rice breeding and testing efforts at AICRIP have enabled the country to generate 1329 varieties between 1966 and 2019 and create an extensive database on rice yields in experiments. This database provides a valuable means of empirically assessing 
the response of rice to environmental variation, and also the genetic gains over years in different ecosystems. Muralidharan et al. $^{3}$ in an earlier study used yield data on genotypes bred from 1974 to 1994 (the first phase) and estimated yield gains of $1.2 \%$ per year or $52 \mathrm{~kg} / \mathrm{ha} /$ year in medium maturing genotypes bred for irrigated ecosystem but attributed this gain to improvement in crop management skills. The trend was negative in upland ecosystem and static or non-significant in genotypes developed for other ecosystems. In a comparative study of the data from global experiments organized by IRRI, Muralidharan et $a l .^{4}$ further confirmed the lack of any genetic gain in the rice genotypes developed anywhere in the world between 1976 and 1997. Estimations on genetic gain in cereals derived quantitatively as $\mathrm{kg} / \mathrm{ha} /$ year (from 23 to 72 ) has more meaningful use than those made as proportion (from $0.3 \%$ to $1.2 \%$ ). These assessments made globally demonstrate the abysmally low genetic gain for yield in cereals.

\section{Division of target rice environment impedes genetic gain}

Our analyses on the performance of genotypes tested in AICRIP during 1995-2013 (the second phase), showed positive, significant increases in top 3 genotypes, check and experimental mean grain yields in semi-deep water, irrigated very early, irrigated early, irrigated medium and irrigated Basmati ecosystems. The quantum of increase in the mean grain yield of top 3 genotypes was marginally higher, similar or less than the check or experimental mean grain yields. While the top 3 genotypes and experimental mean grain yields are derived from sets of many genotypes that vary each year, the means for check is from more or less the same genotype used over years in the respective ecosystem. As the genetic gain derived by subtracting check mean or experimental mean grain yields from top 3 genotypes mean grain yields showed non-significant and nearly static yields in the genotypes (including Basmati genotypes) bred for different ecosystems, it is evident that the only gain made was in crop management skills in these ecosystems with adequate water available for crop growth. A scrutiny made on flowering duration of the genotypes ${ }^{7}$ tested in rainfed upland very early ecosystem (up to $70 \mathrm{DF}$ ) showed that most of the tested genotypes flowered beyond 71 days indicating the classification to be invalid. Similarly genotypes tested in irrigated very early (up to $80 \mathrm{DF}$ ) also showed flowering beyond 81 days. Many such anomalies were also found in other ecosystems. Due to lack of genotypes exclusively bred for an ecosystem, arbitrary nominations for testing are apparently made using opportunity rather than suitability. Ambiguity also exists in using the terms very early and early duration with varied flowering durations for rainfed upland (up to 70 and $71-80 \mathrm{DF}$ respectively) and irrigated ecosystems (up to 80 and $81-90$ DF respectively).
Earlier studies had shown the futility of creating many ecosystems for rice improvement ${ }^{3,4}$. Prasad et al. ${ }^{32}$ analysed the stability and yield of genotypes tested in 1341 national experiments during 1970-1994 (ref. 7) and 1305 international $^{33}$ experiments during 1970-1994. Mean yield, coefficient of variation and other stability indices using regression analyses identified several cultivars, developed at different centres around the globe as stable for yield. These genotypes, with varying genetic makeup that crossed geographic boundaries and spread over ecosystems based on their sensitivity or insensitivity to photoperiod and maturity duration, were identified as universal genotypes for a specific mega-environment. Prasad et $a l{ }^{32}$ therefore regrouped rice habitats or ecosystems into only four mega-environments: (1) rainfed unfavourable uplands requiring very early varieties $(<90 \mathrm{DM})$ with photo-insensitivity; (2) rainfed favourable uplands and irrigated areas requiring early varieties (90-110 DM) with photo-insensitivity; (3) irrigated areas requiring medium varieties (120-135 DM) with photo-insensitivity; and (4) rainfed lowlands requiring late varieties (>140 DM) with photosensitivity or insensitivity. While agreeing with this classification and regrouping many rice ecosystems into four mega-environments, the need for a careful reconsideration on the highly variable rainfed ecosystem was emphasized (G. S. Khush, 2001, IRRI, Philippines, pers. commun.). Yet, AICRIP's breeding for rice improvement was aimed at 11 ecosystems during 1995-2013 (Table 1). In the experiments to compare grain yield performance of these genotypes, 24 varieties were used as checks that included 9 varieties used in the earlier period between 1974 and 1994. Five varieties NDR97, Swarna, Heera, Vandana and Annada were used as checks for more than one ecosystem which further proves the unwarranted sub-division of ecosystems. Only three checks - Dhanrasi, Vandana and Anjali were released after 1995 besides Tarori Basmati, a pure-line Basmati selection known earlier but released only in 1996. None of the checks in any of the AICRIP's experiments during 1974-2013 (Table 2) could exceed the overall mean grain yield of Jaya (4.54 t/ha), a high yielding variety released in 1968 (Figure 7). When compared with their record during 1974-1994, seven old check varieties in fact had improved grain yield performance during 1995-2013. Only the improvement in the cultural and managerial skills is clearly evident in the increased grain yields in checks that were very old and without any periodic change. Evidence on non-availability of checks with higher yields also confirmed the irrational subdivision of ecosystems. There is also a possibility that genetic progress in grain yield was not detected in rice breeding as it was partly countered by climate change, mainly heat stress during grain filling as reported for wheat in Europe ${ }^{12}$ and by changes in the intensity of biotic and abiotic stresses ${ }^{34}$. But for the gain in grain yields, genetic progress has been remarkable in breeding lines 


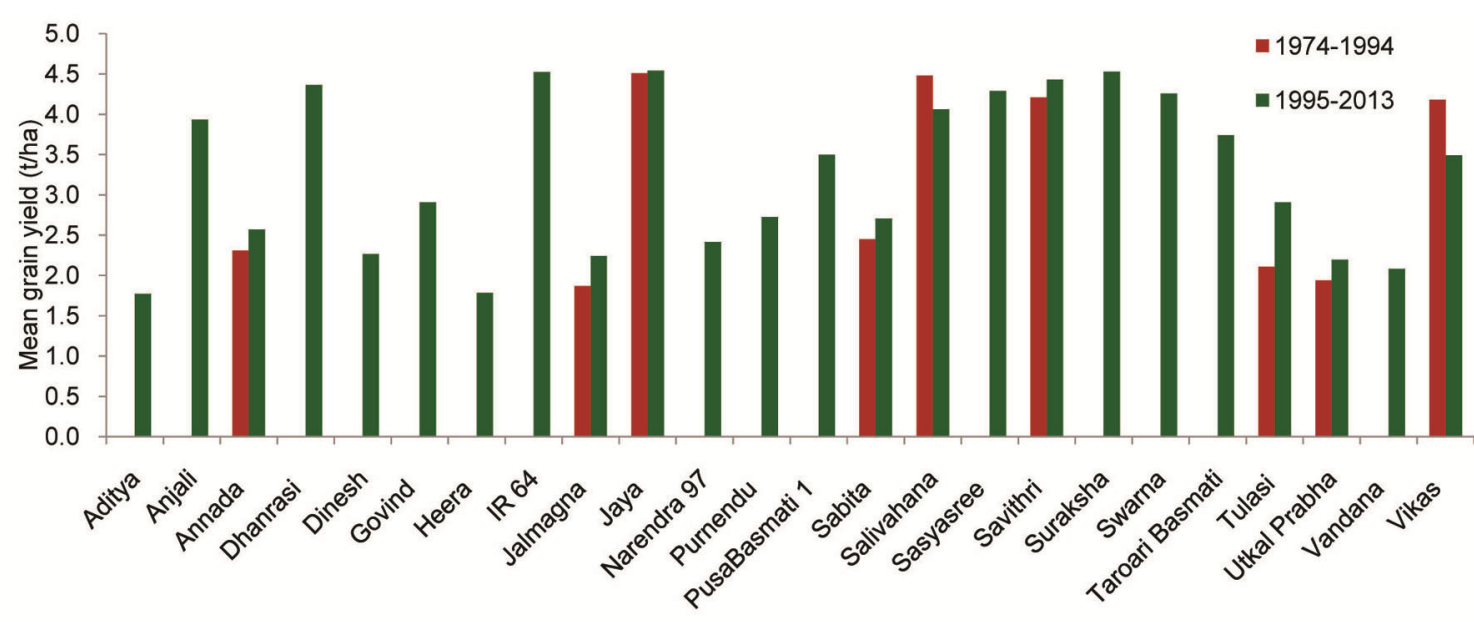

Figure 7. Comparison of mean grain yields (t/ha) of check varieties (40 years from 1974 to 2013).

generated and tested in AICRIP in terms of enhanced tolerance to abiotic and biotic stresses, per day productivity, wide range of maturity duration and grain quality ${ }^{3,4,32}$. Other countries have also benefited from AICRIP's tests by the release and commercial exploitation of India-bred rice varieties ${ }^{35}$.

\section{National production gains in countries}

Crop yields increased remarkably worldwide in the second-half of the last century due to development and extensive adoption of improved crop varieties and recommended crop management with emphasis on balanced and need-based fertilizer use, water management and timely protection from pests through chemical pesticides. In India, access to improved varieties, adoption of location specific management practices, steady investments and pro-agriculture policies strengthened irrigation facilities, mechanization, and agricultural research infrastructure which together contributed to the progressive growth of crop production. Apart from the favourable policies, subsidy on cost of seed, fertilizer, and farm machinery, minimum support price for major crops and access to credit facilities proved as valuable incentives to steadily step-up production and productivity in nearly all major cereal crops. A linear increase was found by Hafner ${ }^{10}$ in rice $(55 \mathrm{~kg} / \mathrm{ha} /$ year $)$, maize $(62 \mathrm{~kg} / \mathrm{ha} /$ year $)$ and wheat (43 kg/ha/year) yields for 188 nations during 1961-2000. The world crop yields between 1988 and 2007 were estimated to have linearly increased at $25 \mathrm{~kg} / \mathrm{ha} /$ year in wheat, $38 \mathrm{~kg} / \mathrm{ha} /$ year in rice and $80 \mathrm{~kg} / \mathrm{ha} /$ year in maize $\mathrm{e}^{36}$. The breeding emphasis has shifted from yield enhancement to defend grain production from biotic and abiotic stresses and improve grain quality. This shift has also diverted resources, principally in wheat and rice ${ }^{17}$, which may account for a significant part of the differences in the rate of global yield increase between maize and the two self-pollinated cereals (rice and wheat). In 2007,
Tang et al. ${ }^{37}$ reported that from 29.2 million ha planted to rice with $95 \%$ area under irrigated ecosystem, China pushed the production to 187 million tonnes of paddy and attained a productivity level of $6.4 \mathrm{t} / \mathrm{ha}$. Fan et al. ${ }^{38}$ concluded that such a rice production growth was possible because of the steadily increased yield per unit area rather than by expansion of area under rice. Varieties with maturity period not less than 125-130 days, and hybrids and super rice varieties which take $>150$ days to mature were widely grown with high fertilizer use. In a field supplemented with organic fertilizer $(2250 \mathrm{~kg} / \mathrm{ha}), 270 \mathrm{~kg} \mathrm{~N} / \mathrm{ha}$ (108: $54: 54: 54$ before transplanting, mid tillering, panicle initiation and spikelet differentiation), plant density $(12.8 \times 25 \mathrm{~cm})$, drainage at mid-tillering, and alternate wetting and moderate soil drying irrigation, only Yangyou 2640 (indica/japonica hybrid) produced the highest levels of panicles $\left(184 / \mathrm{m}^{2}\right)$, spikelets $(337 /$ panicle), filled grains $(81 \%)$, grain weight $(25.4 \mathrm{mg} / 100$ grains $)$ and grain yield $(12.7 \mathrm{t} / \mathrm{ha})^{39} . \mathrm{FAO}^{40}$ reported use of $\sim 200 \mathrm{~kg}$ $\mathrm{N} /$ ha to harvest $6.26 \mathrm{t} / \mathrm{ha}$ in China, $70 \mathrm{~kg} \mathrm{~N} / \mathrm{ha}$ to obtain $6.42 \mathrm{t} / \mathrm{ha}$ in Japan, and $110 \mathrm{~kg} \mathrm{~N} /$ ha to produce $6.26 \mathrm{t} / \mathrm{ha}$ in South Korea. The world's highest national average japonica rice yield in 2005 was $9.5 \mathrm{t} /$ ha from Egypt ${ }^{41}$. In Australia, japonica rice yields in farms (average size 400 ha) ranged from 8 to 12 t/ha (ref. 42).

Rice production in India ${ }^{6}$ has also shown a continued increase (Figures 6 and 8) from 1968 when the country's first high yielding variety Jaya was released. The rice area increased from 37 million hectares ( $\mathrm{m} \mathrm{ha}$ ) in 1968 by $3 \mathrm{~m}$ ha till 1975 and the production of milled rice increased by $9 \mathrm{mt}$. During 1975-1995, rice area further increased by an additional $3 \mathrm{~m}$ ha but the production increased by $28 \mathrm{mt}$. Between 1995 and 2013, despite area remaining at $\sim 43 \mathrm{~m}$ ha, milled rice production rose by $29 \mathrm{mt}$. Unmilled rice productivity had increased in steps, from $1.64 \mathrm{t} / \mathrm{ha}$ in 1968 , to $1.86 \mathrm{t} / \mathrm{ha}$ in 1975 , to $2.73 \mathrm{t} / \mathrm{ha}$ in 1995 , and to $3.76 \mathrm{t} /$ ha in 2013 . Although genetic gain for grain yield was practically absent, AICRIP's impressive 
progress in rice improvement was in insulating varieties to protect national production from biotic and abiotic stresses, delayed onset, excess or deficit in monsoon rains. The stable increase achieved in national rice production in the absence of a genetic gain in yield could be attributed to the continued improvement and wide adoption of crop production skills at farm level. The relative rate of increases in world crop production were predicted to decline in 2007 by $0.9 \%$ per year for wheat and rice, and by $1.6 \%$ per year for maize $\mathrm{e}^{36}$. Our results also show a decline in the rate of growth in national rice grain production during 1995-2013 in India.

\section{Attainable and potential yields}

Concepts proposed by van Ittersum and Rabbinge ${ }^{43}$ on farm yield (FY), attainable yield (AY) and potential yield (PY) are used in yield studies. Theoretical estimate on potential grain yield of rice was predicted at $20.9 \mathrm{t} / \mathrm{ha}$ (ref. 44). When yield potential was estimated using 13-15 years data on US rice production systems, it ranged from 11.5 to $14.5 \mathrm{t} / \mathrm{ha}$, while actual yields varied from 7.4 to $9.6 \mathrm{t} / \mathrm{ha}^{45}$. Attainable yield has come to mean the yield that a skillful farmer should reach when taking prudent account of economics and risk; it has complications because farmers vary, as do farm gate economics. The difference between FY and AY has been defined as the exploitable yield gap. Potential yield was estimated at $15.2 \mathrm{t} / \mathrm{ha}$ for maize, $9.0 \mathrm{t} / \mathrm{ha}$ for rice and $5.5 \mathrm{t} / \mathrm{ha}$ for wheat using data from the global yield gap and water productivity atlas ${ }^{46}$. The attainable yields differ in rice ecosystems, environmental conditions and genotype cultivated. Muralidharan et al. ${ }^{3}$ demonstrated a maximum attainable yield of $10 \mathrm{t} / \mathrm{ha}$ in indica varieties by analysing the data generated by AICRIP. In the globally organized similar experiments, the maximum yield attained was only $10.8 \mathrm{t} / \mathrm{ha}$ (refs 4, 32). Peng et $a .^{14}$ had concluded a

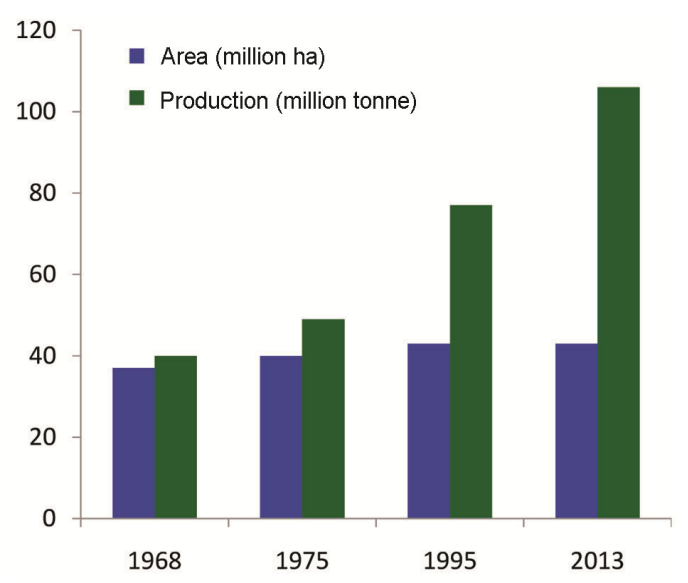

Figure 8. Comparison of rice area (million hectares) and milled rice grain production (million tonnes milled rice) in India during 1968, 1975,1995 and 2013. limit of $9 \mathrm{t} / \mathrm{ha}$ in the wet season and $10 \mathrm{t} / \mathrm{ha}$ in the dry season in the Philippines. In very well managed irrigated trials at IRRI in the absence of significant diseases, insect pests, and weeds this limit to attainable yields was confirmed $^{47}$. Analysis of data on rice or maize (max. of 7.83 or $8.12 \mathrm{t} / \mathrm{ha})$, mungbean $(0.68 \mathrm{t} / \mathrm{ha})$ and wheat $(5.91 \mathrm{t} / \mathrm{ha})$ cropping system from western Indo-Gangetic Plains had revealed the total production of the system at $16.43 \mathrm{t} / \mathrm{ha}$ (ref. 48). Various commercialized hybrids were derived by crossing different varieties within or between two subspecies, Oryza sativa ssp. indica and ssp. japonica ${ }^{49}$. The pioneer super inter subspecies hybrid Xieyou 9308 developed by 3-line and hybrid Liangyoupeijiu (LYP9) by 2-line breeding using temperature sensitive genic male sterile source (Peiai 64S) realized 10.5 t/ha in 2000 (ref. 50). In Japan, the japonica cultivar Takanari released in 1990 was widely assessed in central and southern Honshu, and it gave an average yield of $10.5 \mathrm{t} / \mathrm{ha}, 36 \%$ more than Nipponbare, a landmark cultivar released in 1963 (ref. 51). Yang et al..$^{47}$ compared the best of the inbreds and new plant types 2 (NPT2) with IRRI hybrids and the yields recorded ranged only from 8.29 to $9.55 \mathrm{t} / \mathrm{ha}$. In Taoyuan Township, Yunnan Province, PR China, at $\sim 200 \mathrm{~N} /$ ha applications IR 72 reportedly produced grain yields of $12.7 \mathrm{t} / \mathrm{ha}$ with a grain filling of $78 \%$ and a biomass of $24 \mathrm{t} /$ ha when the NPT2 line produced lesser yield due to low biomass and poor grain filling ${ }^{14}$. Peng et al ${ }^{52}$ showed that the second generation NPT2 lines have also not increased the yield potential. The super rice Liangyoupeijiu gave a maximum grain yield of $12.11 \mathrm{t} / \mathrm{ha}$ (ref. 53). Liangyoupeijiu was grown at 38 testing sites (each of $6.7 \mathrm{ha}$ ). Its grain yield in $150 \pm 24$ days averaged $10.5 \mathrm{t} / \mathrm{ha}$ although a maximum grain yield as high as $15.3 \mathrm{t} / \mathrm{ha}$ was reported in Binchuan County, Yunnan Province, in 1999 (ref. 54). Evidently to harvest grain yields beyond $10 \mathrm{t} / \mathrm{ha}$ in hybrid super rices even in a limited area, adoption of intensive crop management and application of high levels of fertilizers and other inputs will be required. Therefore, it is apparent that the potential yield is limited to $15-16 \mathrm{t} / \mathrm{ha}$ and attainable yield to $10-11 \mathrm{t} / \mathrm{ha}$ with choice cultivars in the best rice growing stress-free environment under intensive management. The combination of high intensity of solar radiation $\left(23 \mathrm{MJ} / \mathrm{m}^{2}\right)$ and low temperature $\left(\sim 16^{\circ} \mathrm{C}\right)$, and extended grain filling phase (for $\sim 40$ days) had contributed to New Zealand's world yield record of $15.6 \mathrm{t} /$ ha using a winter wheat cultivar in the 2010 crop season ${ }^{55}$. Pioneer hybrids in maize yielded $12 \mathrm{t} / \mathrm{ha}$ in Iowa, $\mathrm{USA}^{56}$. Fischer and Edmeads ${ }^{17}$ concluded that when grown early at high densities under irrigation in a very favourable Chilean environment, Pioneer maize hybrids produced $20 \mathrm{t} / \mathrm{ha}$.

\section{Possibilities for increased national production}

Trends in maize, rice and wheat yields worldwide in four decades showed linear and slowing growth ${ }^{10}$. A clear 
linear trend of slowing growth was also detected in our analysis of the national rice production in India between 1995 and 2013. The slowing of production growth is not due to limits of productivity and environmental stresses but due to changes in the availability and access to labour, inputs, subsidies and other social and economic factors. A comparison of the national unmilled rice productivity of $3.76 \mathrm{t} / \mathrm{ha}$ in 2013 (ref. 6) with the recorded attainable yields of $10 \mathrm{t} / \mathrm{ha}$ in India ${ }^{3,4,32}$, reveals an exploitable yield gap of nearly $6 \mathrm{t} / \mathrm{ha}$. Even the mean grain yields of check varieties obtained in the experimental fields across the country were higher than the national productivity of $3.76 \mathrm{t} / \mathrm{ha}$ by 1.0 to $1.5 \mathrm{t} / \mathrm{ha}$ in irrigated (early, mid-early, medium and late including Basmati) ecosystems (Table 2); it was higher by $0.8 \mathrm{t} / \mathrm{ha}$ in rainfed shallow lowland ecosystem. A governmental policy decision and targeted initiative to push yields by a mere $0.5 \mathrm{t} / \mathrm{ha}$, that too limited to about 31 million ha $(20 \mathrm{~m}$ ha in irrigated and $11 \mathrm{~m}$ ha under favourable rainfed lowland ecosystems), can lead India to harvest additionally more than 15 million tonnes of rice. Increased yields at attainable levels in rice will, however, come inevitably at a cost and higher input use. The yield variability is heavily determined by the level of fertilizer use, irrigation, climate and especially seasonal rainfall. Changes to management practices that are needed to close yield gaps vary considerably with region and cropping intensity. Huge increases in water consumption, increased nitrogen fertilizer use with associated environmental impacts, and requirements for non-renewable mineral resources such as potassium and phosphorus are to be expected. Shortages in rice supply will be unavoidable, if annual national rice grain production growth does not return to previous rates or at least at rates to keep production ahead of population growth. Increase in cereal production in recent decades has been achieved mostly from irrigated lands, through the diffusion of improved crop varieties and adoption of region, location or site-specific crop management. The rising costs of irrigation and the problems of management, cost recovery, and the maintenance of existing systems limit any further expansion of irrigation. New growth sectors, such as industry and tourism, as well as increasing population and urbanization all compete for water resources. Silting of reservoirs and canals, lowering of underground water levels, and salinization of irrigated soils are the new constraints to crop production. Considerable investments are vital to remove silt deposits, raise ground-water table, and improve fertilizer and water use efficiency to increase the national production levels to meet the future demands for rice.

World over, including in India, intensive research has decisively added numerous traits in rice to enhance input use efficiency, withstand stress conditions but failed to raise potential yield. Difficulties in using genetic variability and limitations to conventional breeding-selection approaches foil attempts to breach the potential yield of
$10 \mathrm{t} / \mathrm{ha}$. Encouraged by the highest yields achieved in the major cereal crops, to raise the potential yield in rice, innovative approaches are currently being pursued to transfer yield genes still remaining hidden in wild relatives, engineer more productive plant architecture, convert $\mathrm{C} 3$ rice into $\mathrm{C} 4$ plant, manipulate starch biosynthesis and make plants fix nitrogen in symbiotic association with diazotrophs using the new opportunities offered by developments in genomics ${ }^{57}$.

Rapid advances in plant molecular biology leading to sequencing of genome can help mine and use very large number of hitherto unknown gene sources through functional and applied genomics to overcome the genetic constraints to raising yield threshold. Many consider that the future of crop improvement will depend primarily on how the genomic knowledge is used to locate additional or new variability and move the genes of interest across the barriers of sexual incompatibility. Advances in molecular genetics will greatly help to introgress new traits from distant sources. It may take as long a time as conventional breeding to breed a variety of choice by genetic engineering and overcome the hurdles in deregulating for commercial planting. Political decisions and concerns of farmers and environmentalists may extend the minimal 15 -year time lag between gene discovery and seed distribution to farmers.

Despite the power of genomic resources in crop breeding research, the fact remains that the abundant natureprovided variability has not been exhausted for the desired yield improvement. To date, genetic improvements in rice have been through use of empirically obtained phenotypic data, pedigree information and selection. Prediction methods based on data routinely collected by plant breeding programmes are far from exhausted. There remains one constant that will not change, namely, that breeding progress depends on selection accuracy to detect rare genotypes that show new or improved attributes as a result of superior combinations of alleles at multiple loci in the context of a target set of environments ${ }^{58}$. This implies that precise phenotyping will remain as the foundation of future crop improvement. Recent advances in genomic breeding would greatly help conventional breeding in this regard. What is important is a precisely directed breeding to make targeted progress. In this context, it will be more appropriate to restrict breeding and testing efforts of AICRIP to the four mega environments of rice ${ }^{32}$ and focus on raising the potential yield.

Globally, there have been shifts in funding at public institutions to enhance intellectual capacity and infrastructure for genomics research often at the expense of conventional plant breeding ${ }^{59}$. This shift in funding was temporarily needed to establish the foundations for $21 \mathrm{st}$ century plant biology. It is a good sign that there is a growing interest to make use of innovative genomic tools and knowledge in combination with conventional breeding-selection $^{60}$ to move forward in rice improvement 
research. To remain food secure considering the challenge of meeting with future demand projections, priority should be to address the yield gap by exploiting currently available high yielding varieties and continue efforts to vertically raise the genetic yield by integrating conventional and molecular breeding strategies.

\section{Conclusions}

We have demonstrated that intensive rice breeding research since the introduction of plant type based high yielding varieties has definitely not increased grain yield substantially by genetic gain. Nevertheless AICRIP's progress in conventional breeding has added numerous traits of value in rice especially to withstand abiotic and biotic stress conditions and thereby enhanced stability in performance. The effort has insulated national production from delayed onset, excess or deficit in monsoon rains or other climate aberrations and aided in increased production during risk-prone kharif season. Increases in national rice production have confirmed the continued improvement in crop production skills at the farm level along with effective use of irrigation, water-use-efficient varieties and other factors. The focus of rice breeding in future must be restricted to four mega environments namely, rainfed unfavourable uplands (requiring varieties with $<90 \mathrm{DM}$ ), rainfed favourable uplands and irrigated areas (90-110 DM), irrigated areas (120-135 DM) and rainfed lowlands (photosensitive or insensitive $>140 \mathrm{DM}$ ). Use of innovative genomic tools and knowledge in combination with conventional breeding-selection may be an efficient strategy to direct rice improvement and for the desired genetic grain yield enhancement. To remain food secure considering the challenge of meeting with future demand projections, priority should be to address the yield gap in available high yielding varieties and vertically raise the genetic yield by integrating genomic technologies in conventional breeding strategies.

1. Lin, C. S., Binns, M. R. and Lefkovitch, L. P., Stability analysis: Where do we stand? Crop Sci., 1986, 2, 894-900.

2. Jensen, N. F., Floating checks for plant breeding nurseries. Cereal Res. Commun., 1976, 4, 285-295.

3. Muralidharan, K., Prasad, G. S. V. and Rao, C. S., Breeding for rice improvement, where do we stand? Curr. Sci., 1996, 71, 438448.

4. Muralidharan, K., Prasad, G. S. V. and Rao, C. S., Yield performance of rice genotypes in international multi-environment trials during 1976-97. Curr. Sci., 2002, 83, 610-619.

5. Meridth $\mathrm{Jr}$ and Bridge, R. R., In Genetic contribution to yield gains of five major crop plants. Crop Sci. Soc. Am. Spl. Publ., $1984,7,75-87$.

6. GOI, Government of India Agricultural statistics at a glance. Department of Economic and Cooperation, Ministry of Agriculture, Government of India, 2015; http://agricoop.nic.in/agristatisticsnew.html

7. ICAR-IIRR, Annual progress reports 1968-2018, All-India Coordinated Rice Improvement Project (AICRIP). ICAR-Indian Insti- tute of Rice Research (formerly Directorate of Rice Research), Hyderabad, India, 1968-2015.

8. Snedecor, G. W. and Cochran, W. G., Statistical Methods, Oxford \& IBH, New Delhi, 1967.

9. Gomez, K. A. and Gomez, A. A., Statistical procedures for agricultural research with emphasis on rice. International Rice Research Institute, Philippines, 1982.

10. Hafner, S., Trends in maize, rice and wheat yields for 188 nations over the past 40 years, a prevalence of linear growth. Agric. Ecosyst. Environ., 2003, 97(1), 275-283.

11. Gracini, P., Eskridge, K. M. and Cassman, K. G., Distinguishing between yield advances and yield plateaus in historical crop production trends. Nat. Commun., 2013, 4, 2918; doi:10,1038/ ncomms3918] www.nature.com/nature communications

12. Brisson, N., Gate, P., Gouache, D., Carmet, G., Oury, F.-X. and Huard, F., Why are wheat yields stagnating in Europe? A comprehensive data analysis in France. Field Crops Res., 2010, 119, 201212.

13. Gourdji, S. M., Mathews, KyL., Reynolds, M., Crossa, J. and Lobell, D. B., An assessment of wheat yield sensitivity and breeding gains in hot environment. Proc. R. Soc. B. Biol. Sci. 3013, 2014, 280, 20122190.

14. Peng, S., Cassman, K. G., Virmani, S. S., Sheehy, J. and Khush, G. S., Yield potential trends of tropical rice since release of IR8 and challenge of increasing yield potential. Field Crops Res., 1999, 39, 1552-1559.

15. Sanchez-Gracia, M., Royo, C., Aparicio, N., Martin-Sanchez, J. A. and Alvaro, F., Genetic improvement of bread wheat yield and associated traits in Spain during the 20th century. J. Agric. Sci., 2013, 151, 105-118; doi:10.1017/S002189612000330.

16. Beche, E., Benin, G., DaSilva, C. L., Munaro, L. B. and Marchese, J. A., Genetic gain in yield and changes associated with physiological traits in Brazilian wheat during the 20th century. Eur. J. Agron., 2014, 61, 49-59.

17. Fischer, R. A. and Edmeades, G. O., Breeding and cereal yield progress. Crop Sci., 2010, 50, 85-98.

18. Austin, R. B., Ford, M. A. and Mogan, C. L., Genetic improvement in the yield of winter wheat, a further evaluation. J. Agric. Sci., Cambridge, 1989, 112, 295-301.

19. Perry, M. W. and D'Antuono, M. F., Yield improvement and associated characteristics of some Australian spring wheat cultivars introduced between 1860 and 1982. Aust. J. Agr. Res., 1989, 40, $457-472$.

20. DonMez, E., Sears, R. G., Shroyer, J. P. and Paulsen, G. M., Genetic gain in yield attributes of winter wheat in the Great Plains. Crop Sci., 2001, 41, 1412-1419.

21. Morgounov, A. et al., Genetic gains for grain yield in high latitude spring wheat grown in Western Siberia in 1900-2008. Field Crops Res., 2010, 117, 101-112.

22. Brancourt-Hulmel, M., Doussinault, G., Lecomte, C., Berard, P., Le Buanec, B. and Trottet, M., Genetic improvement of agronomic traits of winter wheat cultivars released in France from 1946 to 1992. Crop. Sci., 2003, 43, 37-45.

23. Cox, T. S., Shroyer, R. J., BenHui, L., Sears, R. G. and Martin, T. J., Genetic improvement in agronomic traits of hard red winter wheat cultivars from 1919 to 1987. Crop Sci., 1988, 28, 756-760.

24. Rodrigues, O., Lhanby, J. C. B., Didonet, A. D. and Marchese, J. A., Fifty years of wheat breeding in Southern Brazil, yield improvement and associated changes. Pesq. Agropec. Bras., 2007, 42, 817-825.

25. Mellado, M., El trigo en Chile. Institute of investigations agriculture. Centro Regional de Investigacion Quilamapu. Colleccion Libros INIA, N0 21. Chillan, Chile, 2007, p. 648.

26. Reyes, J. M., Estudio del advance genetico de genotipos de trigo harinero primaveral sembrados en Chille con distintoano delliberacion. Memoria de Titulo Ingeniero Agronomo. Universidad de Talca, Chille, 2009, p. 36. 


\section{RESEARCH ACCOUNT}

27. Zhou, Y., He, Z. H., Chen, X. M., Wang, D. S., Yan, J., Xia, X. C. and Zhang, Y., Genetic improvement of wheat yield potential in North China. In Wheat Production in Stressed Environments (eds Buck, H. T., Nisi, J. E. and Salom, N.), Springer-Verlag, New York, 2007, pp. 583-589.

28. Ahlemeyer, J., Aykut, F., Kohler, W., Friedt, W. and Ordon, F., Genetic gain and genetic diversity in German winter barley cultivars. Options Mediterraneenes SerA, 2005, 81, 43-47.

29. Redaelli, R., Lagana, P., Rizza, F., Nicosia, O. L. D. and Cattivilli, L., Genetic progress of oats in Italy. Euphytica, 2008, 164, 679687.

30. Abeledo, L. G., Calderini, D. F. and Slafer, G. A., Genetic improvement of yield responsiveness to nitrogen fertilization and its physiological determinants in barley. Euphytica, 2003, 133, 291298.

31. Sayeare, K. D., The role of crop management research at CIMMYT in addressing bread wheat yield potential issues. In Increasing Yield Potential in Wheat, Breaking the Barriers (eds Reynolds, M. P., Rajaram, S. and McNab, A.), Mexico, DF, 1996, pp. 203-207.

32. Prasad, G. S. V., Muralidharan, K. and Rao, C. S., Stability and yield performance of genotypes, A proposal for re-grouping world rice area into mega environments. Curr. Sci., 2001, 81, 13371346 .

33. IRRI, International Rice Research Institute, Annual final reports. International Rice Testing Program (IRTP) or, International Network for Genetic Evaluation of Rice (INGER), Philippines, 19761998.

34. ICAR-IIRR, Production oriented survey 1975-2014. All-India Coordinated Rice Improvement Project (AICRIP). ICAR-Indian Institute of Rice Research (formerly Directorate of Rice Research), Hyderabad, India, 1975-2015.

35. Prasad, G. S. V., Prasadarao, U., Rani, N. S., Rao, L. V. S., Pasalu, I. C. and Muralidharan, K., Indian varieties released in countries around the world. Curr. Sci., 2001, 80, 1508-1511.

36. Tweeten, L. and Thomson, S. R., Long-term agricultural output supply-demand and real farm and food prices. Working paper AEDE-WP 0044-08. Ohio State University, Columbus, OH, 2008.

37. Tang, S., Ding, L. and Bonjean, A. P. A., Rice production and genetic improvement in China. In Cereals in China (eds Zhang, H. E. and Bonjean, A. P. A.), DF Mexico, 2010, pp. 15-34. ISBN 978-970-648-177-1

38. Fan, M. et al., Food security. Improving crop productivity and resource efficiency to ensure food security and environmental quality in China. J. Exp. Bot., 2012, 63, 13-24.

39. Zhang, H. et al., Progressive integrative crop managements. Field Crops Res., 2018, 215, 1-11.

40. Food and Agriculture Organization, FAO agricultural database. (www.fao.org), FAO, Rome, Italy, 2004.

41. FAO, 2006; http://www.fao.org/Newsroom/en/news/2006/1000387/ index.html

42. Lacy, J., Clampett, W. and Nagy, J., Bridging the rice yield gap in Australia, FAO document repository, 2000; http://www.fao.org/ docrep/003/x6905e/x6905e06

43. van Ittersum, M. K. and Rabbinge, R., Concepts of production ecology for analysis and quantification of agricultural input-output combinations. Field Crops Res., 1997, 52, 197-208.

44. Siddiq, E. A., Reddy, C. K., Zaman, F. U. and Muralidharan, K., Finding new yield thresholds through changing concept of plant type in rice. In International Dialogue on Perception and Prospects of Designer Rice (eds Muralidharan, K. and Siddiq, E. A.), Society for Advancement of Rice Research, ICAR-Indian Institute of Rice Research, Hyderabad, 2013, pp. 29-38.
45. Espea, M. B. et al., Yield gap analysis of US rice production systems shows opportunities for improvement. Field Crops Res., 2016, 196, 276-283.

46. vanOorta, P. A. J., Saito, K., Grassini, D. P., Cassman, K. G. and van Ittersum, M. K., Can yield gap analysis be used to inform R\&D prioritization? Glob. Food Sec., 2017, 12, 109-118.

47. Yang, W. S., Peng, S., Laza, R. C., Visperas, R. M. and DionisioSese, M. I., Grain yield and yield attributes of new plant type and hybrid rice. Crop Sci., 2007, 47, 1393-1400.

48. Choudhary, K. M. et al., Evaluating alternatives to rice-wheat system in western Indo-Gangetic Plains: Crop yields, water productivity and economic profitability. Field Crops Res., 2018, 218 , $1-10$.

49. Cheng, Z. J., Zhuang, J. Y., Fan, Y. Y., Du, J. H. and Cao, L. Y., Progress in research and development on hybrid rice, a superdomesticate in China. Ann. Bot. (London), 2007, 100(5), 959-966.

50. Yuan, L. P. (ed.), Super Hybrid Rice Research, Shanghai Scientific and Technical Publishers. Shanghai, China, 2006, pp. 2-3.

51. Taylaran, R. D., Ozawa, S., Miyamoto, N., Ookawa, T., Motobayashi, T. and Hirasawa, T., Performance of a high yielding modern rice cultivar Takanakari and several old and new cultivars grown with and without chemical fertilizers in a submerged paddy field. Plant Prod. Sci., 2009, 12, 365-380.

52. Peng, S., Khush, G. S., Virk. P., Tang, Q. and Zou, Y., Progress in ideotype breeding to increase yield potential. Field Crops Res., 2008, 108, 32-38.

53. Yu, C. and Lei, J., Theory and practice of super rice breeding in China. Acta Agric. Jiangxi, 2001, 13, 51-59 (in Chinese with English abs).

54. Lu, C. and Zhou, J., A widely commercialized two-line super hybrid rice, Liangyoupeijiu. Int. Rice Res. Notes, 2003, 28, 20.

55. Guinness World Records, Highest wheat yield, 2003; http://www. guinnessworldrecords.com/world-records/1/highest-wheat-yield

56. Hammer, T. et al., Can changes in canopy and/or root system architecture explain historical maize yield trends in the US corn belt? Crop Sci., 2009, 49, 299-312.

57. Muralidharan, K. and Siddiq, E. A. (eds), International dialogue on perception and prospects of designer rice. Society for Advancement of Rice Research, Directorate of Rice Research, Hyderabad, 2013, p. 386.

58. Sorrels, M. E., Application of new knowledge, technologies and strategies to wheat improvement. Euphytica, 2007, 157, 299-306.

59. Knight, J., Crop improvement, a dying breed. Nature, 2003, 421, 568-570.

60. Rao, P. V., Muralidharan, K. and Siddiq, E. A. (eds), Molecular breeding strategies for crop improvement. Proc. One-day Dialogue, July 2017, Professor Jayashankar Telangana State Agricultural University (PJTSAU), Hyderabad, 2018, p. 250; ISBN 978-81936934-0-7.

ACKNOWLEDGEMENTS. We thank the Director, Indian Institute of Rice Research, Hyderabad, India for support and facilities. We acknowledge the contributions made by breeders at the AICRIP centres in various state agricultural universities in conducting of rice experiments. We also thank Dr G. S. Khush for encouraging us to pursue this research and Dr S. V. S. Shastry for critical comments.

Received 9 October 2015; revised accepted 3 November 2018

doi: $10.18520 / \mathrm{cs} / \mathrm{v} 116 / \mathrm{i} 4 / 544-560$ 